\title{
A general framework for understanding the response of the water cycle to global warming over land and ocean
}

\author{
M. L. Roderick ${ }^{1,2,3, * *}$, F. Sun ${ }^{2,3}$, W. H. Lim ${ }^{2,3,}$, and G. D. Farquhar ${ }^{2,3}$ \\ ${ }^{1}$ Research School of Earth Sciences, The Australian National University, Canberra, ACT 0200, Australia \\ ${ }^{2}$ Research School of Biology, The Australian National University, Canberra, ACT 0200, Australia \\ ${ }^{3}$ Australian Research Council Centre of Excellence for Climate System Science, Canberra, Australia \\ *Currently at: Department of Civil Engineering, Tokyo Institute of Technology, Tokyo, 152-8552, Japan \\ **Invited contribution by M. L. Roderick, recipient of the EGU John Dalton Medal 2013.
}

Correspondence to: M. L. Roderick (michael.roderick@ anu.edu.au)

Received: 22 November 2013 - Published in Hydrol. Earth Syst. Sci. Discuss.: 13 December 2013

Revised: 24 March 2014 - Accepted: 24 March 2014 - Published: 6 May 2014

\begin{abstract}
Climate models project increases in globally averaged atmospheric specific humidity that are close to the Clausius-Clapeyron (CC) value of around $7 \% \mathrm{~K}^{-1}$ whilst projections for mean annual global precipitation $(P)$ and evaporation $(E)$ are somewhat muted at around $2 \% \mathrm{~K}^{-1}$. Such global projections are useful summaries but do not provide guidance at local (grid box) scales where impacts occur. To bridge that gap in spatial scale, previous research has shown that the "wet get wetter and dry get drier" relation, $\Delta(P-E) \propto P-E$, follows CC scaling when the projected changes are averaged over latitudinal zones. Much of the research on projected climate impacts has been based on an implicit assumption that this CC relation also holds at local (grid box) scales but this has not previously been examined. In this paper we find that the simple latitudinal average CC scaling relation does not hold at local (grid box) scales over either ocean or land. This means that in terms of $P-E$, the climate models do not project that the "wet get wetter and dry get drier" at the local scales that are relevant for agricultural, ecological and hydrologic impacts. In an attempt to develop a simple framework for local-scale analysis we found that the climate model output shows a remarkably close relation to the long-standing Budyko framework of catchment hydrology. We subsequently use the Budyko curve and find that the local-scale changes in $P-E$ projected by climate models are dominated by changes in $P$ while the changes in net irradiance at the surface due to greenhouse forcing are small and only play a minor role in changing the mean annual $P-E$ in the climate model projections. To further understand the
\end{abstract}

apparently small changes in net irradiance we also examine projections of key surface energy balance terms. In terms of global averages, we find that the climate model projections are dominated by changes in only three terms of the surface energy balance: (1) an increase in the incoming long-wave irradiance, and the respective responses (2) in outgoing longwave irradiance and (3) in the evaporative flux, with the latter change being much smaller than the former two terms and mostly restricted to the oceans. The small fraction of the realised surface forcing that is partitioned into $E$ explains why the hydrologic sensitivity $\left(2 \% \mathrm{~K}^{-1}\right)$ is so much smaller than CC scaling $\left(7 \% \mathrm{~K}^{-1}\right)$. Much public and scientific perception about changes in the water cycle has been based on the notion that temperature enhances $E$. That notion is partly true but has proved an unfortunate starting point because it has led to misleading conclusions about the impacts of climate change on the water cycle. A better general understanding of the potential impacts of climate change on water availability that are projected by climate models will surely be gained by starting with the notion that the greater the enhancement of $E$, the less the surface temperature increase (and vice versa). That latter notion is based on the conservation of energy and is an underlying basis of climate model projections. 


\section{Introduction}

The water cycle is like a vast heat engine with water evaporating at the surface and the vapour subsequently condensing at relatively colder temperatures high up in the atmosphere before precipitating and thereby closing the atmospheric component of the water cycle. The cycle begins with evaporation that by itself consumes around $80 \%$ or so of the available energy at the surface (Trenberth et al., 2009; Wild et al., 2013). Because of the energetic importance, understanding globalscale changes in climate requires an understanding of globalscale changes in the water cycle. However, the water cycle is not just of interest at the global scale. Many of the key impacts of anthropogenic climate change, e.g. on agriculture, water resources, terrestrial ecology, etc., are projected to occur via changes in water availability. Of particular interest are changes in precipitation $(P)$, evaporation $(E)$ and their difference $(P-E)$. In that respect two key results have emerged from previous syntheses of climate model output. First, the atmospheric specific humidity is projected to increase at the Clausius-Clapeyron (CC) value of around $7 \% \mathrm{~K}^{-1}$ (Held and Soden, 2000). That result is not programmed into the models - rather it emerges and is more or less the same as the original constant relative humidity assumption made by Arrhenius in the first detailed calculations of the impact of changing atmospheric $\mathrm{CO}_{2}$ (Arrhenius, 1896; Ramanathan and Vogelmann, 1997). A second emergent projection from climate models is for global $P$ to increase by around 1 to $3 \% \mathrm{~K}^{-1}$ that is often summarised by the $2 \% \mathrm{~K}^{-1}$ statement (Boer, 1993; Allen and Ingram, 2002). These global scale syntheses are useful because they enable scientists to better understand and interpret the climate model output. More importantly, they offer ongoing opportunities to confront the model projections with observations (e.g. Wu et al., 2013; Wentz et al., 2007; Liepert and Previdi, 2009; Sherwood et al., 2010; Paltridge et al., 2009; Vonder Haar et al., 2012).

Simplifying projected changes in the global water cycle using temperature-based scaling relations is also useful because it readily relates to widely discussed projections and political targets, e.g. a $3 \mathrm{~K}$ increase in globally averaged surface temperature for a doubling of $\mathrm{CO}_{2}$ (IPCC, 2007). However, the global results themselves have little direct application for impact studies because the impacts are local and not global. Some typical questions of direct relevance to impacts include: Will it rain more or less where I live? Or will the runoff increase or decrease in the local catchment over the coming century? Local-scale questions like these cannot be answered using global averages. Simulations and projections of key water cycle variables $(P, E, P-E)$ are readily available at local (grid box) scales for all climate models. For example, the widely used CMIP3 (Coupled Model Intercomparison Project Phase 3) simulations and projections are summarised in the Global Water Atlas (Lim and Roderick, 2009). Similar summaries are expected to become available shortly for the newly developed CMIP5 archive. Those summaries faithfully represent the simulations and projections, but for scientific understanding, some level of synthesis is desirable.

Held and Soden (2006) extended the globally averaged results by studying changes projected to the end of the 21 st century in the latitudinal (i.e. zonal) averages of key water and energy variables. Using a multi-model ensemble mean derived from CMIP3 models they uncovered a simple relation where the projected change in $P-E$ in each latitudinal zone scaled with $P-E$, i.e. $\Delta(P-E) \propto P-E$, where the scaling coefficient was the $\mathrm{CC}$ value $\left(7 \% \mathrm{~K}^{-1}\right)$ multiplied by the temperature difference. In attempting to summarise their result they used the phrase the "wet get wetter and dry get drier". By that they meant that if $P-E$ was greater than zero, then one could consider the surface to have a surplus of water (i.e. the hydrologic equivalent of runoff) and in that sense it was wet. Further, the change, $\Delta(P-E)$, would have the same sign $( \pm)$ as $P-E$, hence the wet get wetter (and vice versa). That definition has some problems when trying to interpret land and ocean changes in a single integrative framework (see below). Despite that difficulty, the emergent relation remains an important insight for climate science because one can readily understand projected changes in the zonally averaged poleward transport of heat and moisture from the zonally averaged projected changes in $P-E$ (Held and Soden, 2006).

Given the now widespread use of the "wet get wetter and dry get drier" phrase it is important to briefly revisit, and understand, what the results presented by Held and Soden (2006) actually showed. Their zonal averages included both ocean and land. At most latitudes, $P$ and $E$ are dominated by exchanges over the ocean (Oki and Kanae, 2006; Lim and Roderick, 2009) and zonal averages will be mostly determined by exchanges over the ocean. Held and Soden (2006, p. 5693) were well aware of this limitation and also noted the key difference between land and ocean; over land the long-term average $E$ must be less than or equal to $P$. In contrast, water is always available for evaporation over the ocean and $E$ is not constrained by $P$. This creates a problem for interpreting the results. In particular, if we adopt their definition of wet, i.e. $P-E \geq 0$, then all land is classified as wet as is around half the ocean while the remaining part of the ocean will be defined as dry. That is clearly an unsatisfactory basis for interpretation. More generally, the different behaviour of land and ocean with respect to the water cycle makes it difficult to treat land and ocean in one common interpretive framework (Roderick et al., 2012). Given that the zonal averages are dominated by the oceanic components, it follows that the $\Delta(P-\mathrm{E}) \propto P-E$ relation should be mostly relevant to the ocean. With that in mind, we reinterpret the Held and Soden (2006) result by first noting that the ocean surface is always wet irrespective of the values of $P$ and $E$. Instead, $P-E$ is a useful index of the salinity status of the surface ocean water (Durack et al., 2012). On that basis, a better description of their finding is that the fresh get fresher and salty get saltier. Two important questions arise. 
Table 1. Mean annual water balance over the globe, ocean and land simulated at the end of the 20th century (1970-1999, 20C3M) and the changes projected to the end of the 21st century (2070-2099, A1B). The percentages are shown below the projected changes. Note that the change in global mean surface temperature between the two periods is $+2.8 \mathrm{~K}$, giving a projected change in global $P$ (and $E$ ) of $(4.5 \% / 2.8 \mathrm{~K}=) 1.6 \% \mathrm{~K}^{-1}$.

\begin{tabular}{|c|c|c|c|c|c|c|c|}
\hline \multirow[t]{2}{*}{ Region } & \multirow{2}{*}{$\begin{array}{l}\text { Area } \\
\left(\times 10^{14} \mathrm{~m}^{2}\right)\end{array}$} & \multicolumn{3}{|c|}{$1970-1999(20 \mathrm{C} 3 \mathrm{M})$} & \multicolumn{3}{|c|}{ 2070-2099 (A1B) } \\
\hline & & $P$ & $\begin{array}{c}E \\
\left(\mathrm{~mm} \mathrm{a}^{-1}\right)\end{array}$ & $P-E$ & $\Delta P$ & $\begin{array}{l}\Delta E \\
\left(\mathrm{~mm} \mathrm{a}^{-1}\right)\end{array}$ & $\Delta(P-E)$ \\
\hline GLOBE & 5.09 & 1045 & 1045 & 0 & $\begin{array}{l}47 \\
{[4.5 \%]}\end{array}$ & $\begin{array}{l}47 \\
{[4.5 \%]}\end{array}$ & $\begin{array}{l}0 \\
{[0 \%]}\end{array}$ \\
\hline OCEAN & 3.62 & 1153 & 1248 & -95 & $\begin{array}{l}50 \\
{[4.3 \%]}\end{array}$ & $\begin{array}{l}58 \\
{[4.7 \%]}\end{array}$ & $\begin{array}{l}-8 \\
{[8.4 \%]}\end{array}$ \\
\hline LAND & 1.47 & 775 & 542 & +233 & $\begin{array}{l}41 \\
{[5.3 \%]}\end{array}$ & $\begin{array}{l}20 \\
{[3.7 \%]}\end{array}$ & $\begin{array}{l}+21 \\
{[9.0 \%]}\end{array}$ \\
\hline
\end{tabular}

First, does the fresh get fresher and salty get saltier framework hold at individual grid boxes over the ocean? Second, is it possible to synthesise the model projections over land in terms of either zonal averages, or more importantly, for the individual grid boxes, because the latter is the relevant scale for assessing climate impacts.

The aim of this paper is to address the two above-noted questions. To maintain consistency in the interpretation we use the same climate model output (CMIP3) as originally used by Held and Soden (2006) and follow their analysis by focusing on changes in the mean annual water and surface energy balances over climatic timescales (here we use $30 \mathrm{yr}$ averages). The paper begins with a brief overview of projected changes in the water cycle for the globe, and for land and ocean separately, and then tests whether the previous zonally averaged results for changes in $P-E$ also hold at local (grid box) scales. We then extend earlier work by incorporating projected changes in the surface energy balance and show that the climate model projections over land conform closely to the long-established Budyko framework of catchment hydrology (Budyko, 1948, 1974, 1982). We finalise the paper by presenting a novel framework that moves beyond the simple temperature-based scaling of the hydrologic impact of climate change to a more general surface energy balance framework. That new perspective is used to understand how projected changes in the water cycle are simultaneously related to projected changes in greenhouse-induced surface forcing and surface temperature in climate models.

\section{Climate model simulations and projections}

Following Held and Soden (2006), we use the same output from IPCC AR4 models available in the CMIP3 archive for the 20th century simulations (20C3M scenario) and 21st century projections (A1B scenario) (Meehl et al., 2007). A multi-model ensemble mean $\left(2.5^{\circ} \times 2.5^{\circ}\right.$ spatial resolution $)$ was constructed using 39 runs from 20 different climate models for precipitation $(P)$ and evaporation $(E)$. Full details of all individual model runs (including maps and summary tables) are available in the Global Water Atlas (Lim and Roderick, 2009). The mean annual water balance is represented by averages calculated for both the 1970-1999 and 2070-2099 periods. We also calculated averages over the same time periods for all surface energy balance terms (units: $\left.\mathrm{W} \mathrm{m}^{-2}\right)$; incoming $\left(R_{\mathrm{S}, \mathrm{i}}\right)$ and outgoing $\left(R_{\mathrm{S}, \mathrm{o}}\right)$ short-wave and long-wave $\left(R_{\mathrm{L}, \mathrm{i}}, R_{\mathrm{L}, \mathrm{o}}\right)$ irradiance as well as the latent (LE, with $L\left(\mathrm{~J} \mathrm{~kg}^{-1}\right)$ the latent heat of vaporisation and $E$ $\left(\mathrm{kg} \mathrm{m}^{-2} \mathrm{~s}^{-1}\right)$ the evaporation rate) and sensible $(H)$ heat fluxes. The rate of change in enthalpy $(G)$ is calculated as the residual of the above terms.

The hydrologic analysis (Sects. 3 and 4) uses the traditional depth units for $P$ and $E$ (mm per annum, $\mathrm{mm} \mathrm{a}^{-1}$ ) whilst the surface energy balance analysis (section 5 ) is based on energetic units (all heat fluxes have units $\mathrm{W} \mathrm{m}^{-2}$ ). In that sense $E$ in the hydrologic analysis (units: $\mathrm{mm} \mathrm{a}^{-1}$ ) is related to LE in the energetic analysis (units: $\mathrm{W} \mathrm{m}^{-2}$ ) via the latent heat of vaporisation and the density of liquid water.

\section{Projected changes in the water cycle over land and ocean}

\subsection{Changes in $P$ and $E$ over land and ocean}

Projected changes for the globe and for the ocean and land components are summarised in Table 1. Global $P$ and $E$ are both projected to increase by around $4.5 \%$ by the end of the 21st century. The global mean surface temperature change (per the A1B scenario used here) is $2.8 \mathrm{~K}$ and the projected change in global $P$ and $E$ is equivalent to $1.6 \% \mathrm{~K}^{-1}$ and consistent with results noted elsewhere (Boer, 1993; Allen and Ingram, 2002). As expected the projection shows that $P$ increases faster than $E$ over land leading to more runoff (Nohara et al., 2006) with the ocean behaving in the opposite fashion as must happen to ensure global mass balance. In preparing Table 1 we have ignored changes in the atmospheric water content (i.e. humidity) because that makes 

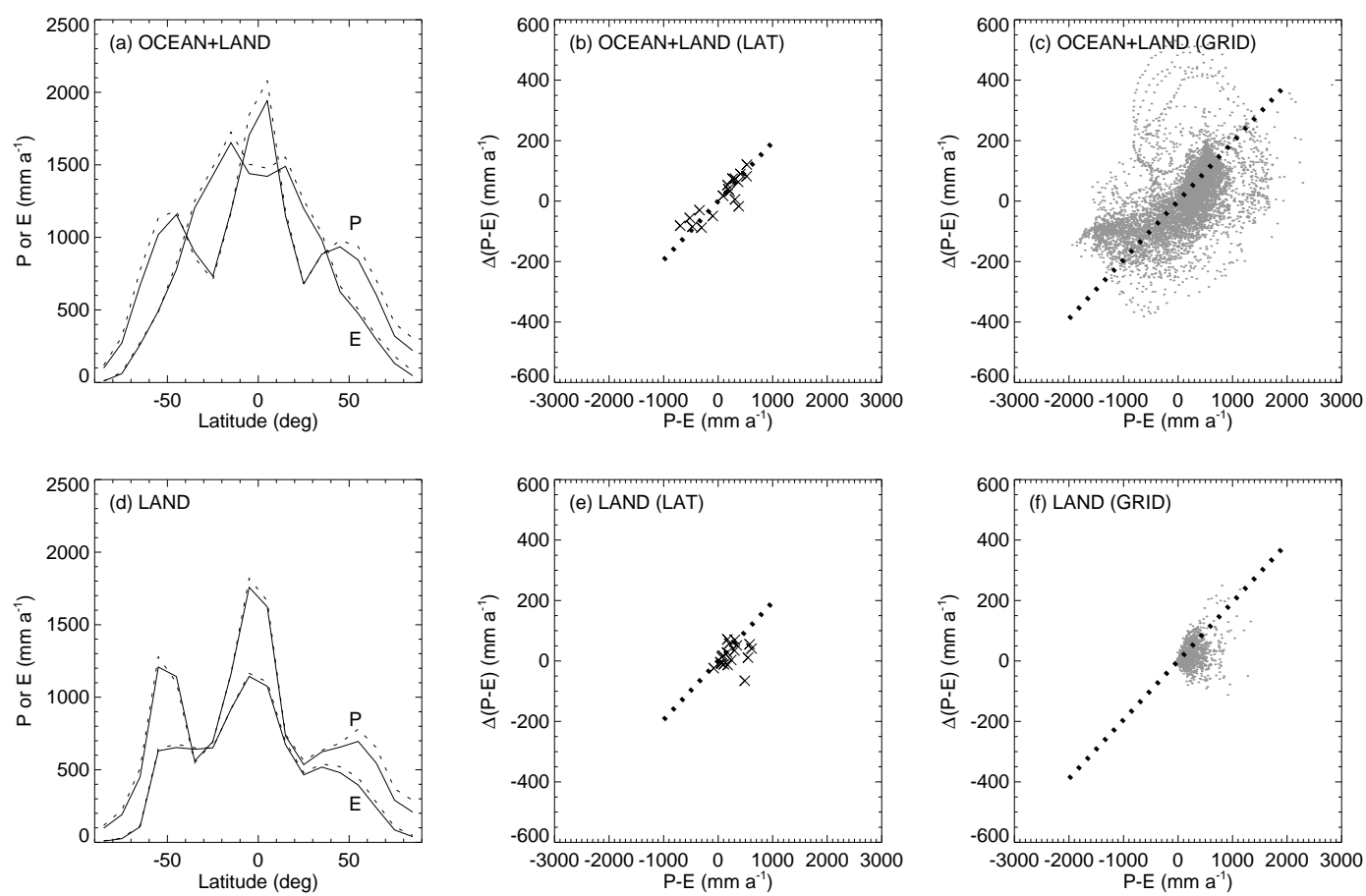

Fig. 1. Annual average $P$ and $E$ over the (top panels) globe (land plus ocean) and over (bottom panels) land. (a) Latitudinal distribution of $P, E$ at the end of the 20th (1970-1999, 20C3M) (full) and 21st (2070-2099, A1B) (dotted) centuries. (b) $\Delta(P-E)$ versus $P-E$ averaged over $10^{\circ}$ latitudinal zones. (c) $\Delta(P-E)$ versus $P-E$ at individual grid boxes. (d), (e), (f) Equivalent plots restricted to the land component. Dotted line (b), (c), (e), (f) highlights the Held and Soden (2006) prediction $\left(\Delta(P-E)=0.07 \mathrm{~K}^{-1} \times 2.8 \mathrm{~K} \times(P-E)=0.20 \times(P-E)\right)$.

little difference to the overall mass balance. In particular, the globally averaged water content of the atmosphere is around $30 \mathrm{~kg} \mathrm{~m}^{-2}$ when expressed per unit of global surface (Oki and Kanae, 2006; Wentz et al., 2007; Vonder Haar et al., 2012). The equivalent depth of liquid water is $30 \mathrm{~mm}$ and is projected to change by some $7 \% \mathrm{~K}^{-1}$. Hence for a warming of $2.8 \mathrm{~K}$, the projected change in the mass of water in the atmosphere is $(30 \times 0.07 \times 2.8=) 5.9 \mathrm{~mm}$ (equivalent depth of liquid water). Taken over the $100 \mathrm{yr}$ period under consideration here, the change is too small $\left(=5.9 \mathrm{~mm} / 100 \mathrm{a}=0.059 \mathrm{~mm} \mathrm{a}^{-1}\right)$ to have a measurable impact on either the global mean annual $P$ or $E$. This raises an interesting point - the absolute change in water content of the atmosphere plays little role in the global mass balance but that same change leads to a substantial fraction of the global warming projected by the climate models via the so-called positive water vapour feedback (Held and Soden, 2000; Russell et al., 2013). We will return to this important point in the Discussion and Conclusions (Sect. 6).

Our results confirm the original $\Delta(P-E) \propto P-E$ relation for zonal averages (Held and Soden, 2006) (Fig. 1b). We find that this relation does not hold over the land component (Fig. 1e). At individual grid boxes there is no relation between $\Delta(P-E)$ and $(P-E)$ over either ocean or land (Fig. 1c, 1f). We conclude that the original scaling relation, $\Delta(P-E) \propto(P-E)($ Fig. 1b) is of most relevance over the ocean and only applies to zonal averages. It is not applicable at local (grid box) scales over either the ocean or land.

\subsection{Relating $P$ and $E$ over land using the Budyko curve}

In terms of the mean annual water balance, water is always available for evaporation over the ocean and $E$ there can be larger than $P$, whilst over land, $E \leq P$. At individual grid boxes the multi-model ensemble mean respects those physical facts (Fig. 2a and d). Over land, the most general approach relating to $E$ to $P$ is the Budyko (supply-demand) framework (Budyko, 1948, 1974; Turc, 1954; Mezentsev, 1955; Pike, 1964; Fu, 1981; Milly, 1994; Dooge et al., 1999; Koster and Suarez, 1999; Choudhury, 1999; Zhang et al., 2001; Arora, 2002; Yang et al., 2007, 2008; Gerrits et al., 2009; Roderick and Farquhar, 2011; Donohue et al., 2011; Renner and Bernhofer, 2012). On that approach the (steady state) partitioning of $P$ between $E$ and runoff ( $=P-E$ here) is treated as a functional balance between the supply of water from the atmosphere $(P)$ and a constraint on the upper limit for $E$, here denoted $E_{\mathrm{o}}$, and defined as the liquid water equivalent of the net irradiance $\left(=R_{\mathrm{N}} / L\right) . R_{\mathrm{N}}$ is calculated from the multimodel ensemble mean $\left(R_{\mathrm{N}}=R_{\mathrm{S}, \mathrm{i}}-R_{\mathrm{S}, \mathrm{o}}+R_{\mathrm{L}, \mathrm{i}}-R_{\mathrm{L}, \mathrm{o}}\right)$. We use the Mezentsev-Choudhury-Yang equation (Mezentsev, 1955; Choudhury, 1999; Yang et al., 2008) to calculate $E$, 

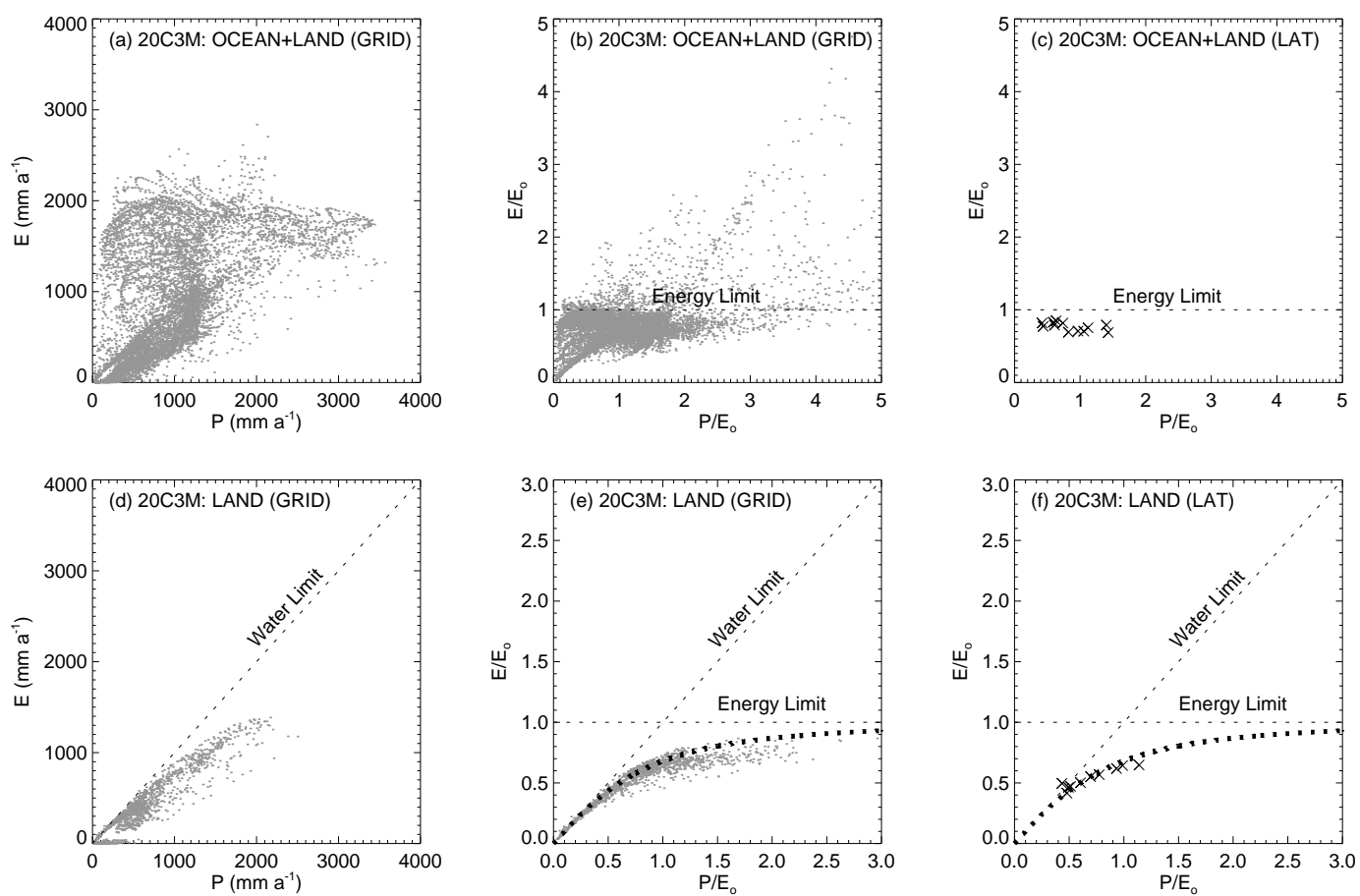

Fig. 2. Relation between mean annual $P$ and $E$ over the (top panels) globe (land plus ocean) and over (bottom panels) land. All climate model output are for the end of the 20th century (1970-1999). Model output for (a) $P, E$ at individual grid boxes (b) normalised by the net irradiance $\left(E_{\mathrm{O}}\right)$, and (c) averaged over $10^{\circ}$ latitudinal zones. (d), (e), (f) Equivalent plots restricted to the land component. The energy $\left(E / E_{\mathrm{O}}=1\right)$ and water $(E \leq P)$ limits are discussed in the main text. The dotted curve in (e) and (f) is the predicted Budyko curve (Eq. (1)) with the default value of the parameter $(n=1.8$, Choudhury, 1999). (Note: in e a better fit is obtained using $n=1.5$ but adopting that value does not materially change the subsequent results or conclusions.)

$E=\frac{P E_{\mathrm{o}}}{\left(P^{n}+E_{\mathrm{o}}^{n}\right)^{1 / n}}$

where $n$ is the catchment properties parameter that modifies the partitioning of $P$ between $E$ and runoff (see Roderick and Farquhar, 2011 for full details). In catchments studied to date the values of $n$ range from 0.6 to 3.6 but most fall within a smaller range of 1.5 to 2.6 (Choudhury, 1999; Yang et al., 2007, 2008; Donohue et al., 2011). Setting $n=1.9$ reproduces the original Budyko curve (Donohue et al., 2011). Note that a higher value of $n$ implies a higher value of $E$ for given $P$ and $E_{\mathrm{o}}$.

Equation (1) has a strong foundation, being based on mass and energy conservation and the fact that when $E$ is waterlimited (e.g. desert), $E \rightarrow P$, and when $E$ is energy-limited (e.g. tropical rainforest), $E \rightarrow E_{\mathrm{o}}$. Note that over the ocean, large quantities of heat can be advected (by ocean currents) and $E_{\mathrm{o}}$ does not set a useful upper limit at local (grid box) scales (Fig. 2b). $E_{\mathrm{o}}$ does set a limit at the global scale (Allen and Ingram, 2002; O'Gorman and Schneider, 2009), and in the model output, $E_{\mathrm{O}}$ sets a limit to $E$ over the ocean in the zonal averages (Fig. 2c).

We use Eq. (1) to calculate $E$ at individual grid boxes over land and express the result using a traditional Budyko diagram. The result at the grid box scale is stunning (Fig. 2e). It is important to note here that this is an independent test since the climate models do not use the Budyko curve to calculate the partitioning of water and heat at the surface. They cannot - the Budyko framework only applies to long-term averages (Donohue et al., 2007). Rather, each climate model solves the surface energy and water balance and steps (usually every $15 \mathrm{~min}$ ) through time. When aggregated to $30 \mathrm{yr}$ averages our results show that the multi-model ensemble mean conforms to the Budyko framework. We also aggregated the land data into $10^{\circ}$ latitudinal zones and this also conforms to the Budyko curve (Fig. 2f). This is not a surprise given the results in Fig. 2e. In particular, the Budyko framework is based on the fundamentals of mass and energy conservation and the asymptotic limits inherent to the approach transfer across spatial scales. In that sense the result shown in Fig. $2 \mathrm{f}$ simply follows from Fig. 2e. We also tested the Budyko framework using climate model output for the end of the 21 st century (2070-2099, A1B) and found almost identical results (not shown). 


\section{Understanding projected changes in the water cycle over land}

The fact that the climate model output conforms to the Budyko framework at grid box scales (Fig. 2e) is useful. Firstly, it establishes that over climatic time scales, the partitioning of $P$ between $E$ and runoff $(=P-E)$ in climate models is consistent with nearly a century of accumulated hydrologic experience embodied in the Budyko curve. Secondly, it opens up the possibility of using the Budyko framework to unravel the model projections of hydrologic change at the surface into the underlying causes. For that we use the differential form of the Budyko curve (Roderick and Farquhar, 2011),

$\mathrm{d} E=\frac{\partial E}{\partial P} \mathrm{~d} P+\frac{\partial E}{\partial E_{\mathrm{o}}} \mathrm{d} E_{\mathrm{o}}+\frac{\partial E}{\partial n} \mathrm{~d} n$,

with the partial differentials given by

$$
\begin{aligned}
& \frac{\partial E}{\partial P}=\frac{E}{P}\left(\frac{E_{\mathrm{o}}^{n}}{P^{n}+E_{\mathrm{o}}^{n}}\right), \\
& \frac{\partial E}{\partial E_{\mathrm{o}}}=\frac{E}{E_{\mathrm{o}}}\left(\frac{P^{n}}{P^{n}+E_{\mathrm{o}}^{n}}\right), \\
& \frac{\partial E}{\partial n}=\frac{E}{n}\left(\frac{\ln \left(P^{n}+E_{\mathrm{o}}^{n}\right)}{n}-\frac{\left(P^{n} \ln P+E_{\mathrm{o}}^{n} \ln E_{\mathrm{o}}\right)}{P^{n}+E_{\mathrm{o}}^{n}}\right) .
\end{aligned}
$$

Note that the partial differentials are all functions of the existing climate $\left(P, E_{\mathrm{o}}\right)$ and the catchment properties parameter $(n)$. We further note that century-scale changes in the catchment properties parameter $(\mathrm{d} n)$ are likely related to changes in vegetation (Roderick and Farquhar, 2011; Donohue et al., 2012). Given that the climate models (in the CMIP3 archive) do not simulate changes in land cover we assume no change in the parameter value $(\mathrm{d} n=0)$. With that assumption, the change in $P-E$ is given by

$\mathrm{d}(P-E)=\varepsilon_{\mathrm{P}} \mathrm{d} P-\varepsilon_{\mathrm{o}} \mathrm{d} E_{\mathrm{o}}$

with the sensitivity coefficients defined by

$\varepsilon_{\mathrm{P}}=1-\frac{\partial E}{\partial P}, \quad \varepsilon_{\mathrm{o}}=\frac{\partial E}{\partial E_{\mathrm{o}}}$.

(See Appendix A for a physical interpretation of this sensitivity framework using an alternate mathematical form of the Budyko curve.) The Budyko framework is not intended for use in the cryosphere since additional long-term mass balance terms (snow/ice) violate the mass balance assumptions. We limit the calculations to the latitudinal range $60^{\circ} \mathrm{S}$ to $60^{\circ} \mathrm{N}$.

The results show that the theoretically based estimate (Fig. 3e) more or less replicates the model output (Fig. 3f). In more detail, $\Delta(P-E)$ is generally much more sensitive to variations in $\Delta P$ (Fig. 3a) than to variations in $\Delta E_{\mathrm{o}}$ (Fig. 3b), as expected (Roderick and Farquhar, 2011; Donohue et al., 2011). Differences in $\Delta P$ between individual grid boxes can be large (range -267 to $+579 \mathrm{~mm} \mathrm{a}^{-1}$ ) with the change, averaged over all grid boxes, of $+53 \mathrm{~mm} \mathrm{a}^{-1}\left( \pm\{1 \mathrm{sd}\} 89 \mathrm{~mm} \mathrm{a}^{-1}\right)$. The spatial variations in $\Delta E_{\mathrm{o}}$ are smaller (range -30 to $+185 \mathrm{~mm} \mathrm{a}^{-1}$ ) with the change, averaged over all grid boxes, of $+47 \mathrm{~mm} \mathrm{a}^{-1}$ $\left( \pm\{1 \mathrm{sd}\} 30 \mathrm{~mm} \mathrm{a}^{-1}\right)$. Because the sensitivity of $\Delta(P-E)$ to change in $\Delta E_{\mathrm{o}}$ is relatively smaller (Fig. 3b), and the variations in $\Delta E_{\mathrm{o}}$ are also relatively small (Fig. 3d), the final predicted map of $\Delta(P-E)$ is dominated by the sensitivity to, and variations in, $\Delta P$.

The theoretical predictions of $\Delta(P-E)$ (Fig. 3e) are compared with the changes projected over the land surface by the climate models (Fig. 3f) in Fig. 4. The theoretical model accounts for around $82 \%$ of the variation in the global climate model (GCM) projections of $\Delta(P-E)$ over the global land surface (Fig. 4c). Note that $\Delta(P-E)$ is more or less independent of the variations due to changes in $E_{\mathrm{o}}$ (Fig. 4b) and is instead dominated by the variations due to changes in $P$ (Fig. 4a) confirming our earlier deductions. (See Appendix A for a physically based interpretation of that result.) In simple terms, whether $P-E$ increases or decreases in a given place depends mostly on changes in $P$.

\section{Understanding projected changes in the surface water and energy balance}

The results of the theoretical analysis (Sect. 4) showed that most of the grid box scale projected changes in $P-E$ were due to changes in $P$ with limited impact due to variations in $E_{\mathrm{o}}$. There was very little spatial structure in the maps of $\Delta E_{\mathrm{o}}$ (Fig. 3d) consistent with the notion of an increase in wellmixed greenhouse gases but we noted only a small change in $E_{\mathrm{o}}\left(+47 \pm 30 \mathrm{~mm} \mathrm{a}^{-1}\right.$, mean $\left.\pm 1 \mathrm{sd}\right)$ despite the fact that the projected increase in global mean surface temperature is nearly $3 \mathrm{~K}$. Understanding why the projected changes in $E_{\mathrm{O}}$ are so small is the key to understanding why $P$ and $E$ are apparently so insensitive to changes in greenhouse forcing in the climate models. That is the focus of this section.

\subsection{Projected changes in the surface energy balance}

The surface energy balance is defined as

$R_{\mathrm{S}, \mathrm{i}}-R_{\mathrm{S}, \mathrm{o}}+R_{\mathrm{L}, \mathrm{i}}-R_{\mathrm{L}, \mathrm{o}}-\mathrm{LE}-H-G=0$,

with incoming and outgoing short-wave $\left(R_{\mathrm{S}, \mathrm{i}}, R_{\mathrm{S}, \mathrm{o}}\right)$ and long-wave $\left(R_{\mathrm{L}, \mathrm{i}}, R_{\mathrm{L}, \mathrm{o}}\right)$ irradiance being balanced by the latent (LE) and sensible $(H)$ heat fluxes while the rate of change in enthalpy (positive into the surface) is denoted $G$. To help understand why the projected change in net irradiance $R_{\mathrm{N}}\left(=R_{\mathrm{S}, \mathrm{i}}-R_{\mathrm{S}, \mathrm{o}}+R_{\mathrm{L}, \mathrm{i}}-R_{\mathrm{L}, \mathrm{o}}\right)$ is small, we compiled estimates of the surface energy balance variables from the multi-model ensemble mean for the two periods in question (Table 2). 

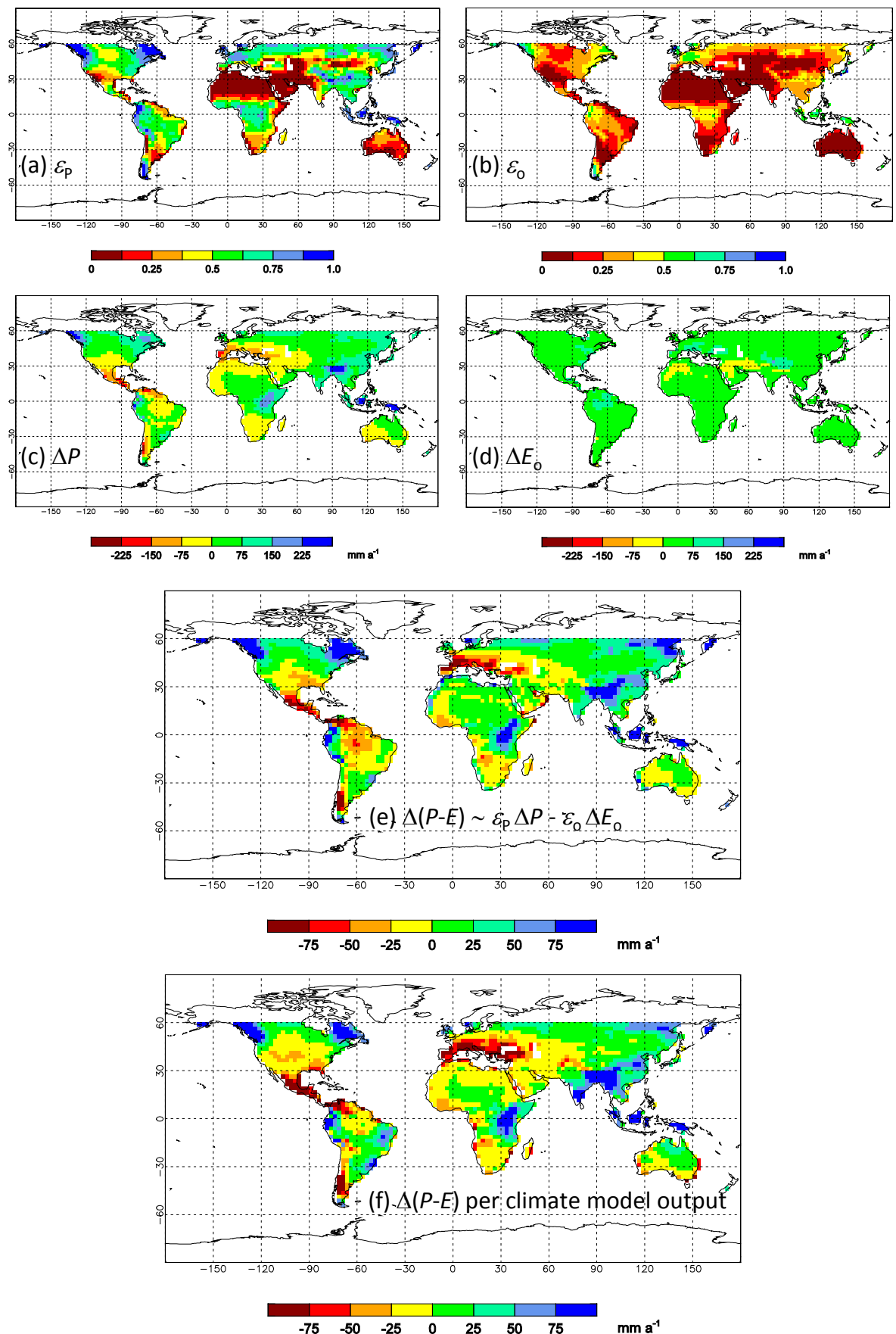

Fig. 3. Comparison of $\Delta(P-E)$ estimated using the Budyko-based framework versus $\Delta(P-E)$ calculated from climate model output. Components of the Budyko-based approach include (a) $\varepsilon_{\mathrm{P}}$ (Eq. (4)), (b) $\varepsilon_{\mathrm{O}}$ (Eq. (4)), (c) $\Delta P$ (per climate model output), (d) $\Delta E_{\mathrm{O}}$ (per climate model output) and the (e) calculated change, $\Delta(P-E) \sim \varepsilon_{\mathrm{P}} \Delta P-\varepsilon_{\mathrm{O}} \Delta E_{\mathrm{O}}$ (Eq. (4)) compared with (f) $\Delta(P-E)$ calculated directly from the climate model output.

In terms of the climatology (1970-1999) the magnitudes of terms in the simulated surface energy balance are generally consistent with current understanding (Trenberth et al., 2009; Wild et al., 2013) (Table 2, also see Fig. 5 for a summary of changes between the two time periods). At the outset we focus on understanding changes in the global energy balance and consider any differences between land and ocean later. For a perfect blackbody at $286.8 \mathrm{~K}\left(=13.6^{\circ} \mathrm{C}, 1970\right.$ 1999 , Table 2) we expect the outgoing long-wave flux would increase by around $\left(\mathrm{d} R_{\mathrm{L}, \mathrm{o}} / \mathrm{d} T=4 \sigma T^{3} \sim 5.4 \mathrm{~W} \mathrm{~m}^{-2} \mathrm{~K}^{-1}\right)$ $5.4 \mathrm{~W} \mathrm{~m}^{-2}$ for every $1 \mathrm{~K}$ surface temperature increase. Hence for the projected $2.8 \mathrm{~K}$ surface $T$ increase (Table 2 ) we expect 

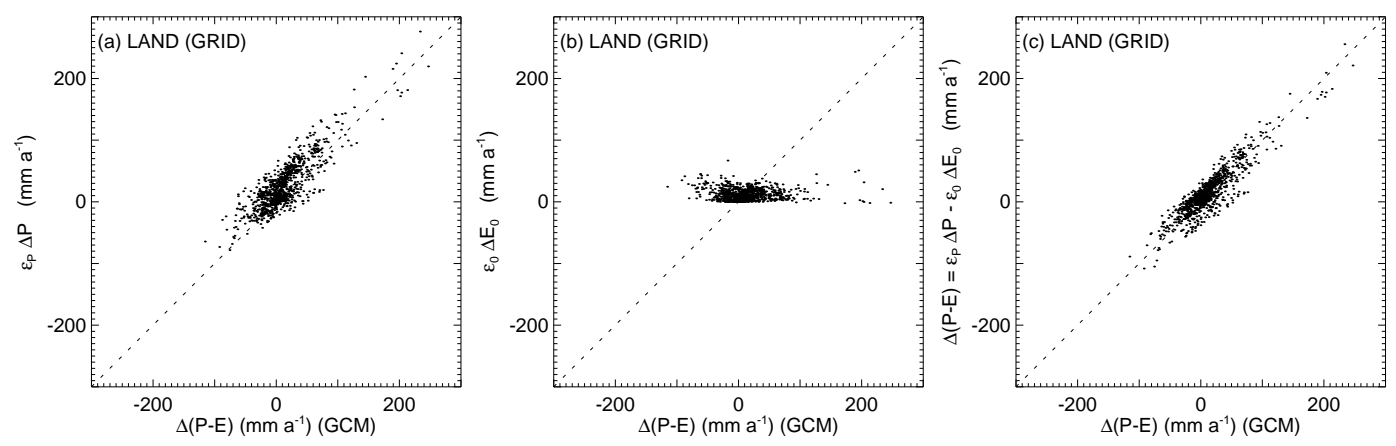

Fig. 4. Comparison between components of the change predicted by the theory with changes projected by the global climate multi-model ensemble mean (GCM). Change in $P-E$ due to change in (a) the rainfall $\left(\varepsilon_{\mathrm{P}} \Delta P\right)$ (regression: $\left.y=0.89 x+13.8, R^{2}=0.72, N=1119\right)$, (b) the evaporative term $\left(\varepsilon_{\mathrm{O}} \Delta E_{\mathrm{O}}\right)$ (regression: $\left.y=0.01 x+9.8, R^{2}=0.00, N=1119\right)$ and the (c) total calculated change $(\Delta(P-E)$ $\left.=\varepsilon_{\mathrm{P}} \Delta P-\varepsilon_{\mathrm{O}} \Delta E_{\mathrm{O}}\right)$ (regression: $\left.y=0.89 x+4.0, R^{2}=0.82, N=1119\right)$ versus the GCM estimates of $\Delta(P-E)$.

Table 2. Surface energy balance components for the globe, ocean and land simulated at the end of the 20th century (1970-1999, 20C3M) and projected to the end of the 21st century (2070-2099, A1B). Areas (globe, ocean, land) are listed in Table 1. T, near-surface air temperature; $R_{\mathrm{S}, \mathrm{i}}$, incoming short-wave irradiance; $R_{\mathrm{S}, \mathrm{o}}$, outgoing short-wave irradiance; $R_{\mathrm{L}, \mathrm{i}}$, incoming long-wave irradiance; $R_{\mathrm{L}, \mathrm{o}}$, outgoing long-wave irradiance; $R_{\mathrm{N}}\left(=R_{\mathrm{S}, \mathrm{i}}-R_{\mathrm{S}, \mathrm{o}}+R_{\mathrm{L}, \mathrm{i}}-R_{\mathrm{L}, \mathrm{o}}\right)$, net irradiance; LE, latent heat flux; $H$, sensible heat flux; $G$, rate of change in enthalpy.

\begin{tabular}{|c|c|c|c|c|c|c|c|c|c|c|}
\hline Region & Period & $\begin{array}{r}T \\
\left({ }^{\circ} \mathrm{C}\right)\end{array}$ & $\begin{array}{r}R_{\mathrm{S}, \mathrm{i}} \\
\left(\mathrm{W} \mathrm{m}^{-2}\right)\end{array}$ & $\begin{array}{r}R_{\mathrm{S}, \mathrm{o}} \\
\left(\mathrm{W} \mathrm{m}^{-2}\right)\end{array}$ & $\begin{array}{r}R_{\mathrm{L}, \mathrm{i}} \\
\left(\mathrm{W} \mathrm{m}^{-2}\right)\end{array}$ & $\begin{array}{r}R_{\mathrm{L}, \mathrm{o}} \\
\left(\mathrm{W} \mathrm{m}^{-2}\right)\end{array}$ & $\begin{array}{r}R_{\mathrm{N}} \\
\left(\mathrm{W} \mathrm{m}^{-2}\right)\end{array}$ & $\begin{array}{r}\mathrm{LE} \\
\left(\mathrm{W} \mathrm{m}^{-2}\right)\end{array}$ & $\begin{array}{r}H \\
\left(\mathrm{~W} \mathrm{~m}^{-2}\right)\end{array}$ & $\begin{array}{r}G \\
\left(\mathrm{~W} \mathrm{~m}^{-2}\right)\end{array}$ \\
\hline \multirow[t]{3}{*}{ GLOBE } & 1970-1999 & 13.6 & 185.8 & 25.5 & 335.2 & 392.0 & 103.5 & 82.3 & 20.0 & 1.3 \\
\hline & 2070-2099 & 16.4 & 184.1 & 23.8 & 353.8 & 406.8 & 107.3 & 86.0 & 18.9 & 2.4 \\
\hline & $\Delta$ & 2.8 & -1.7 & -1.7 & 18.6 & 14.8 & 3.8 & 3.7 & -1.1 & 1.1 \\
\hline \multirow{3}{*}{ OCEAN } & 1970-1999 & 15.8 & 183.6 & 16.2 & 349.3 & 402.1 & 114.7 & 98.3 & 15.2 & 1.2 \\
\hline & 2070-2099 & 18.2 & 181.8 & 14.8 & 366.6 & 414.9 & 118.7 & 102.9 & 13.2 & 2.7 \\
\hline & $\Delta$ & 2.4 & -1.8 & -1.4 & 17.3 & 12.8 & 4.0 & 4.6 & -2.0 & 1.5 \\
\hline \multirow[t]{3}{*}{ LAND } & 1970-1999 & 8.3 & 191.3 & 48.4 & 300.4 & 367.2 & 76.0 & 42.7 & 31.8 & 1.5 \\
\hline & 2070-2099 & 12.1 & 189.8 & 46.1 & 322.1 & 386.8 & 79.0 & 44.3 & 33.1 & 1.6 \\
\hline & $\Delta$ & 3.8 & -1.5 & -2.3 & 21.7 & 19.6 & 3.0 & 1.6 & 1.3 & 0.1 \\
\hline
\end{tabular}

$\Delta R_{\mathrm{L}, \mathrm{o}}$ to be around $+15.1 \mathrm{~W} \mathrm{~m}^{-2}$. The model projection is very close to that value $\left(+14.8 \mathrm{~W} \mathrm{~m}^{-2}\right)$ implying that the global surface is very close to a blackbody (as expected). There is a projected reduction in short-wave irradiance arriving at the surface $\left(\Delta R_{\mathrm{S}, \mathrm{i}}=-1.7 \mathrm{~W} \mathrm{~m}^{-2}\right)$ that is exactly offset by a reduction in short-wave irradiance leaving the surface $\left(\Delta R_{\mathrm{S}, \mathrm{o}}=-1.7 \mathrm{~W} \mathrm{~m}^{-2}\right)$ because of a decrease in surface albedo. Consequently, there is no net change in the absorbed short-wave irradiance and any change in the global net irradiance $\left(R_{\mathrm{N}}\right)$ can only be due to change in the long-wave components. The projection is for a small reduction in the sensible heat flux $\left(\Delta H=-1.1 \mathrm{~W} \mathrm{~m}^{-2}\right)$ with an equivalent rate of increase in enthalpy $\left(\Delta G=+1.1 \mathrm{~W} \mathrm{~m}^{-2}\right)$ that is almost entirely located in the ocean (Table 2) as expected (Pielke Sr., 2003; Levitus et al., 2005). With those relatively minor changes out of the way, the major changes in the surface energy balance are in the incoming and outgoing long-wave irradiance with a smaller residual change in the latent heat flux that is mostly restricted to the global ocean (Fig. 5). What is critical in terms of changes to the water cycle is the ultimate fate of the increase in incoming long-wave irradiance. In the multi-model ensemble mean, most of that increase is simply returned to the atmosphere by an increase in outgoing longwave irradiance $\left(\Delta R_{\mathrm{L}, \mathrm{o}}=+14.8 \mathrm{~W} \mathrm{~m}^{-2}\right)$ with only a small residual fraction being partitioned into a non-radiative component - the latent heat flux $\left(L \Delta E=+3.7 \mathrm{~W} \mathrm{~m}^{-2}\right)$. In summary, the reason that models project relatively small changes in global $E$ (and hence $P$ ) is that the models partition a small fraction of the increase in incoming long-wave irradiance into the latent heat flux. Instead, the increased incoming long-wave irradiance mostly increases the outgoing longwave irradiance. In essence, in the climate model projections, most of the realised surface (radiative) forcing is in the longwave part of the spectrum and is not transformed into another type of energy such as a convective flux.

The same basic pattern, i.e. a large increase in incoming long-wave irradiance $\left(\Delta R_{\mathrm{L}, \mathrm{i}}\right)$ that is mostly partitioned into outgoing long-wave irradiance $\left(\Delta R_{\mathrm{L}, \mathrm{o}}\right)$ with a smaller residual increase in $L \Delta E$, also holds separately over land and ocean although there are some relatively minor differences 


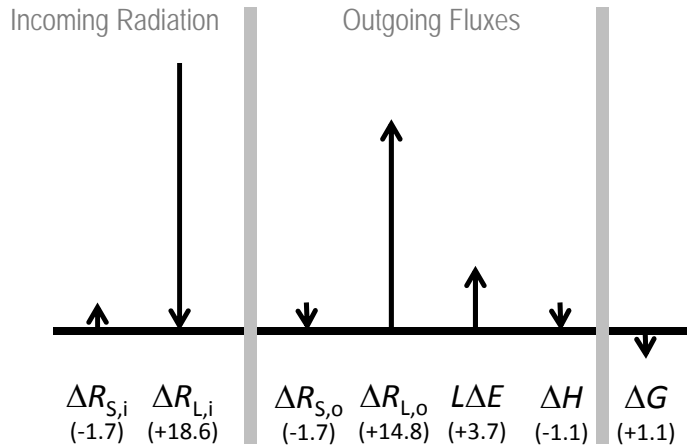

(a) GLOBE $(\triangle T=2.8 \mathrm{~K})$

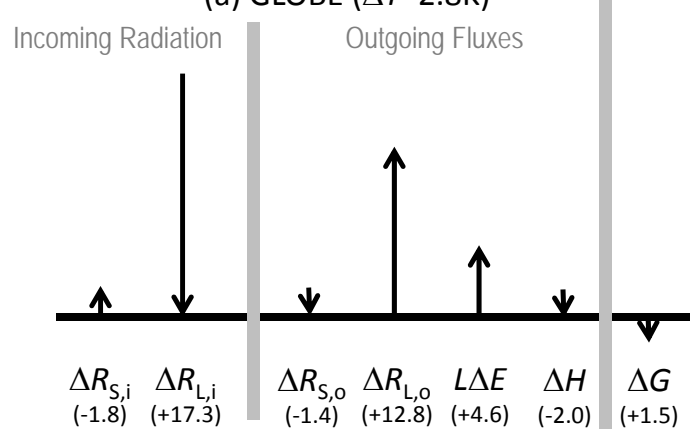

(b) OCEAN $(\Delta T=2.4)$

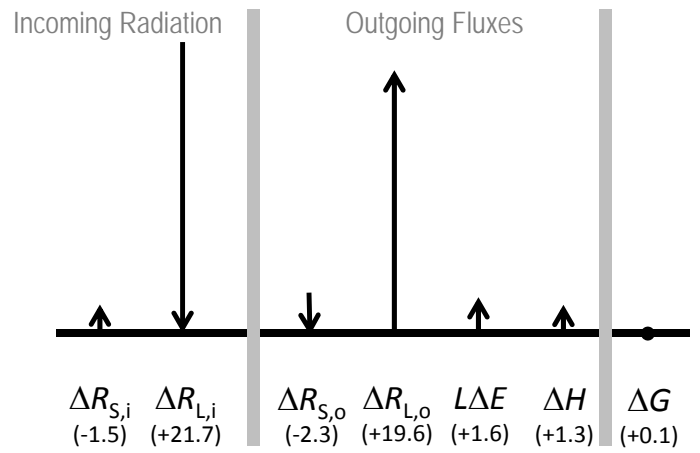

(c) LAND $(\Delta T=3.8 \mathrm{~K})$

Fig. 5. Stylised diagram showing projected changes (2070-2099 less 1970-1999) in components of the surface energy balance (units: $\mathrm{W} \mathrm{m}^{-2}$ ) over the (a) globe, (b) ocean and (c) land. Data are from Table 2. Projected changes in (left) incoming radiation (short-wave, $\Delta R_{\mathrm{S}, \mathrm{i}}$; long-wave, $\Delta R_{\mathrm{L}, \mathrm{i}}$ ) are separated from (middle) changes in the outgoing radiative $\left(\Delta R_{\mathrm{S}, \mathrm{o}}, \Delta R_{\mathrm{L}, \mathrm{o}}\right)$ and convective $(L \Delta E, \Delta H)$ fluxes and from (right) the rate of change in enthalpy $(\Delta G) . \Delta T$ (below each panel) denotes the surface temperature change.

between land and ocean (Fig. 5). Over the ocean there are slight reductions in both incoming and outgoing solar radiation with a small overall reduction in absorbed solar radiation $\left(\Delta R_{\mathrm{S}, \mathrm{i}}-\Delta R_{\mathrm{S}, \mathrm{o}}=-1.8-(-1.4)=-0.4 \mathrm{~W} \mathrm{~m}^{-2}\right)$, and a larger reduction in the sensible heat flux $\left(\Delta H=-2.0 \mathrm{~W} \mathrm{~m}^{-2}\right)$, while virtually all of the global increase in enthalpy occurs in the ocean
$\left(\Delta G=+1.5 \mathrm{~W} \mathrm{~m}^{-2}\right)$. In contrast, over land there are slight increases in absorbed solar radiation $\left(=\Delta R_{\mathrm{S}, \mathrm{i}}-\Delta R_{\mathrm{S}, \mathrm{o}}=-1.5-(-2.3)=+0.8 \mathrm{~W} \mathrm{~m}^{-2}\right) \quad$ while the fraction of the increase in incoming long-wave irradiance $\left(\Delta R_{\mathrm{L}, \mathrm{i}}=+21.7 \mathrm{~W} \mathrm{~m}^{-2}\right)$ partitioned into the outgoing long-wave irradiance $\left(\Delta R_{\mathrm{L}, \mathrm{o}}=+19.6 \mathrm{~W} \mathrm{~m}^{-2}\right)$ is larger, with only a very small residual energy flux available to enhance the latent $\left(L \Delta E=+1.6 \mathrm{~W} \mathrm{~m}^{-2}\right)$ and sensible $\left(\Delta H=+1.3 \mathrm{~W} \mathrm{~m}^{-2}\right)$ heat fluxes. Those minor differences aside, the key finding is that the globally averaged increase in incoming long-wave irradiance at the surface $\left(\Delta R_{\mathrm{L}, \mathrm{i}}\right)$ is mostly partitioned into the outgoing long-wave irradiance $\left(\Delta R_{\mathrm{L}, \mathrm{o}}\right)$ with a small and essentially residual increase in the latent heat flux $(L \Delta E)$.

\subsection{Synthesis}

For the purposes of understanding model projections of changes in the global water cycle it is clear from the previous analysis that we can ignore changes in the short-wave radiative components, the sensible heat flux and the rate of change in enthalpy. With that, we approximate the global projected change by

$\Delta R_{\mathrm{L}, \mathrm{i}} \approx \Delta R_{\mathrm{L}, \mathrm{o}}+L \Delta E$.

For the climate change projection being considered here, we previously noted that global $P$ (and $E$ ) increases by $1.6 \% \mathrm{~K}^{-1}$ and the average $T$ increase is $2.8 \mathrm{~K}$ (Table 1 ). What has not been readily apparent before is that this simple two statement summary $\left(\Delta P=1.6 \% \mathrm{~K}^{-1}, \Delta T=2.8 \mathrm{~K}\right)$ already contains all of the information needed to reconstruct the projected changes in the global surface energy balance.

To see that, we first define the incremental flux ratio,

$x=\frac{L \Delta E}{\Delta R_{\mathrm{L}, \mathrm{o}}}$.

Combining that with Eq. (6), the evaporative fraction of the increase in incoming long-wave irradiance is given by

$\frac{L \Delta E}{\Delta R_{\mathrm{L}, \mathrm{i}}}=\frac{x}{1+x}$,

and the remaining thermal fraction is

$\frac{\Delta R_{\mathrm{L}, \mathrm{o}}}{\Delta R_{\mathrm{L}, \mathrm{i}}}=\frac{1}{1+x}$.

The key point is that one can readily convert a statement on the $\%$ change in $P$ per degree of warming into an estimate of $x$. In addition, the projected surface warming gives the increase in outgoing long-wave irradiance. Combining those two pieces of information allows one to reconstruct the projected change. To do that we first note that the change in global $P$ is equal to the change in global $E$ and that a surface warming of $1 \mathrm{~K}$ is equivalent to an increase in the outgoing 
blackbody irradiance $\left(\mathrm{d} R_{\mathrm{L}, \mathrm{o}} / \mathrm{d} T=4 \sigma T^{3} \sim 5.4 \mathrm{~W} \mathrm{~m}^{-2} \mathrm{~K}^{-1}\right)$ of $5.4 \mathrm{~W} \mathrm{~m}^{-2}$. Setting global $E$ as $82.3 \mathrm{~W} \mathrm{~m}^{-2}$ (Table 2), the $1.6 \% \mathrm{~K}^{-1}$ increase in global $E$ can be converted to an estimate of $x$ as follows:

$x=\frac{1.6}{100}(82.3) \frac{1}{5.4}=(1.6)(0.15)=0.24$.

With $x=0.24$, the incremental evaporative and thermal fractions (Eq. (8)) are respectively

$$
\begin{aligned}
& \frac{L \Delta E}{\Delta R_{\mathrm{L}, \mathrm{i}}}=\frac{0.24}{1+0.24}=0.19 \\
& \frac{\Delta R_{\mathrm{L}, \mathrm{o}}}{\Delta R_{\mathrm{L}, \mathrm{i}}}=\frac{1}{1+0.24}=0.81 .
\end{aligned}
$$

For $\Delta T=2.8 \mathrm{~K}$, the increase in outgoing blackbody long-wave from the surface $\Delta R_{\mathrm{L}, \mathrm{o}}$ is $(5.4 \times 2.8=)+15.1$ $\mathrm{W} \mathrm{m}^{-2}$. With $x=0.24$ (Eq. 9), $L \Delta E$ will be $(0.24 \times$ $15.1=)+3.6 \mathrm{~W} \mathrm{~m}^{-2}$ and the increase in incoming longwave irradiance $\Delta R_{\mathrm{L}, \mathrm{i}}$ is $(15.1+3.6=)+18.7 \mathrm{~W} \mathrm{~m}^{-2}$. This independent reconstruction is very similar to the values calculated directly from the multi-model ensemble mean (Table 2, $\Delta R_{\mathrm{L}, \mathrm{i}}=+18.6 \mathrm{~W} \mathrm{~m}^{-2}, \quad \Delta R_{\mathrm{L}, \mathrm{o}}=+14.8 \mathrm{~W} \mathrm{~m}^{-2}$, $L \Delta E=+3.7 \mathrm{~W} \mathrm{~m}^{-2}$ ).

One important consequence of the energy balance framework used here is that it makes it clear that any increase in evaporation will reduce the surface temperature increase (and vice versa). We can express that physical relation by rewriting Eq. (6) as

$$
\begin{aligned}
\Delta R_{\mathrm{L}, \mathrm{i}} & \approx \Delta R_{\mathrm{L}, \mathrm{o}}+L \Delta E=4 \sigma T^{3} \Delta T+L \Delta E \\
& \Rightarrow \Delta T \approx \frac{\Delta R_{\mathrm{L}, \mathrm{i}}-L \Delta E}{4 \sigma T^{3}} .
\end{aligned}
$$

The inter-relationships between changes in the incoming $\left(\Delta R_{\mathrm{L}, \mathrm{i}}\right)$ and outgoing $\left(\Delta R_{\mathrm{L}, \mathrm{o}}, L \Delta E\right)$ fluxes, the change in surface temperature and the percentage enhancement in the global $P$ are summarised in Fig. 6. Note that if global $P$ (and hence $E$ ) did turn out to increase at the $\mathrm{CC}$ value of $7 \% \mathrm{~K}^{-1}$ (e.g. Wentz et al., 2007) instead of the $1.6 \% \mathrm{~K}^{-1}$ as per the projection considered here, then the increase in surface temperature would be smaller at around $+1.7 \mathrm{~K}$ (Fig. 6).

\section{Discussion and conclusions}

Our study confirms that in the climate models, the relation $\Delta(P-E) \propto P-E$ holds in terms of zonal averages over the ocean, with the scaling coefficient being the ClausiusClapeyron $(\mathrm{CC})$ value $\left(7 \% \mathrm{~K}^{-1}\right)$ multiplied by the temperature difference (Fig. 1b) (Held and Soden, 2006). Further investigations showed that this relation does not hold at the grid box scale over the ocean (Fig. 1c) or the land (Fig. 1f). That is important. For example, imagine one were to identify a scaling relation like $\Delta(P-E) \propto P-E$ based on CC scaling in local scale (e.g. grid box) observations. Such a result would actually constitute a falsification of the climate

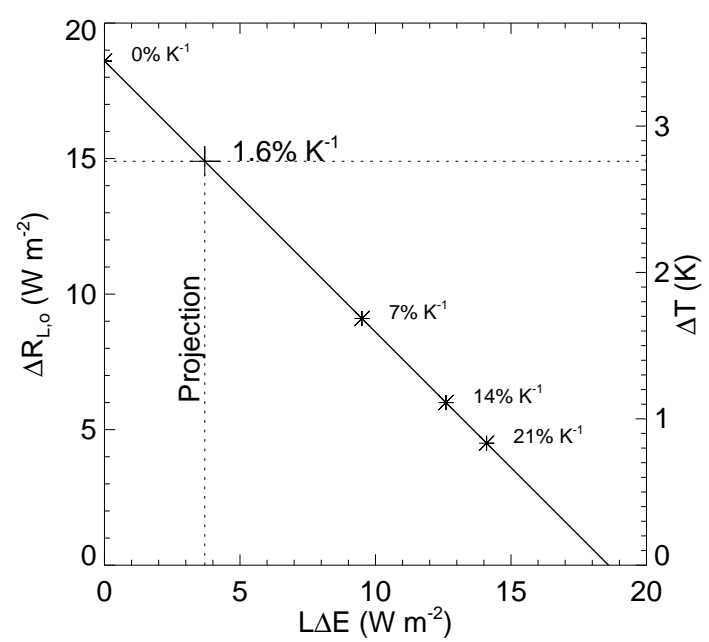

Fig. 6. Relation between global projected change in the latent heat flux $(L \Delta E)$ and outgoing long-wave irradiance $\left(\Delta R_{\mathrm{L}, \mathrm{o}}\right)$ for a given increase in incoming long-wave irradiance $\left(\Delta R_{\mathrm{L}, \mathrm{i}} \approx \Delta R_{\mathrm{L}, \mathrm{o}}+L \Delta E=18.6 \mathrm{~W} \mathrm{~m}^{-2}\right)$. Equivalent surface temperature changes are noted (right-hand axis) as are the percentage enhancements in global $P$ per Kelvin.

model projections. In that respect what the climate models project is an emergent scale-dependent (zonal) relation that is useful to help understand projected changes in the zonally averaged poleward transport of heat and moisture (Held and Soden, 2006). But that same relation does not hold at local grid box scales and is therefore not a useful summary of impacts at the local scale. We note that it would have been a real surprise if the simple relation, $\Delta(P-E) \propto P-E$, based on CC scaling did hold anywhere over land because that simple relation has never previously been identified in observations that span more than a century of hydrologic research (Blöschl et al., 2013).

To test an alternative approach to synthesise the model projections over land we found that the climate model projections closely follow the long-standing Budyko framework (Fig. 2). The Budyko curve emerged at both local grid box scales (Fig. 2e) and in zonal averages (Fig. 2f). This new result establishes that the climate model projections of $P-E$ and $\Delta(P-E)$ accord with more than a century of catchment research experience (Blöschl et al., 2013). It is also very useful because one can use differential forms of the Budyko framework (Roderick and Farquhar, 2011; also see Appendix A) to unravel the underlying basis of the projected response. The differential form introduced here is $\Delta(P-E)=\varepsilon_{\mathrm{P}} \Delta P-\varepsilon_{\mathrm{o}} \Delta E_{\mathrm{o}}$ where the sensitivity terms $\left(\varepsilon_{\mathrm{P}}\right.$, $\left.\varepsilon_{0}\right)$ are calculated as a function of the existing climate $(P$, $E_{\mathrm{o}}$ ) with $E_{\mathrm{o}}$ defined as the evaporative equivalent of the net irradiance. This approach accounts for most of the variation in the model projections (Figs. 3e, f and 4). Further analysis showed that most of the variation in $\Delta(P-E)$ was actually due to the $\varepsilon_{\mathrm{P}} \Delta P$ term (Fig. $4 \mathrm{a}$ ). Here we used the 
multi-model ensemble mean but we note that there are large differences in $\Delta P$ projections at the grid box scale between different models, and, sometimes, between different runs of the same model (Rotstayn et al., 2007; Lim and Roderick, 2009). It is for this reason that local (grid box) scale rainfall projections show the largest between-model differences of all hydro-climatic variables (Johnson and Sharma, 2009). Hence, while the grid box scale projections for $P$ may be highly uncertain, the results presented here show that the multi-model ensemble mean does in fact partition local $P$ between $E$ and runoff in a manner consistent with experience. Whether the output from each individual climate model follows the Budyko framework remains a topic for future research. Perhaps the Budyko framework used here may prove useful for rapidly identifying individual climate models with poorly performing surface water and energy balance schemes.

Our results show that the "wet get wetter dry get drier" idea does not hold in terms of projected changes in the mean annual water balance over land (Fig. 1). Instead a reasonable rule of thumb for the land surface that can adequately account for climate model projections is $\Delta(P-E) \sim \varepsilon_{\mathrm{P}} \Delta P$ with the sensitivity term $(\varepsilon \mathrm{P})$ varying from near unity in wet regions where $P-E$ is relatively large to near zero in dry regions where $P-E \rightarrow 0$ (Fig. 3, also see Appendix A). In the simplest possible terms our results show that when wet and dry are defined by $P-E$, the dry regions are projected to remain dry while wet regions could become either wetter or drier depending on any change in $P$. That result is also clearly evident in earlier maps for the land surface (see Fig. 7 in Held and Soden, 2006). It is straightforward to calculate $\varepsilon \mathrm{P}$ from existing climatic data and the grand challenge is to estimate $\Delta P$.

Our analysis was set in terms of the mean annual water balance and does not contain any information on the intraannual (e.g. seasonal) variations that are so important from a variety of perspectives. Recent findings using the CMIP5 archive have been used to argue that the "wet get wetter dry get drier" idea holds for intra-annual (i.e. seasonal) variations in climate model projections out to the year 2100 (Kumar et al., 2014). That study used the same multi-model ensemble mean approach as we have and reported that at a given place, $P-E$ is projected to increase at wet times of the year but is projected to decrease during dry times of the year (Kumar et al., 2014). Those conclusions relate specifically to intra-annual (i.e. seasonal) differences. One obvious conclusion from the Kumar et al. (2014) finding is that one would project the base flow to decrease whilst the high flows should increase. When integrated over the land surface and over a full year, the increases in high flow would have to be larger than the decreases in low flow so that the long-term mean annual runoff could still increase to maintain an overall increase in $P-E$ over land (Table 1). In contrast, observations of the intra-annual streamflow from the United States for the second half of the 20th century show important regional variations but the overall trend tends to be the opposite of the above-noted model projections with increases in base flow and little change in high flows and an associated reduction in the extremes being reported (Lins and Slack, 1999, 2005). One important point to keep in mind is that real (as opposed to modelled) streamflows are subject to human modifications (e.g. extraction for irrigation, reservoir storage/release, etc.) that are not yet routinely included in global climate models. In that respect we note that at local and regional scales it is already clear that effects of human modifications in many river basins (Grafton et al., 2013) are substantially larger than those of the projected climate changes.

Returning to the model projections, we expected, and found, that the perturbed evaporative term $\left(\varepsilon_{0} \Delta E_{0}\right)$ would show little spatial variation (Fig. 3d) in line with a global forcing induced by well-mixed greenhouse gases. However, after 100 years the perturbation $\left(\varepsilon_{\mathrm{o}} \Delta E_{\mathrm{o}}\right)$ remained small with an average over all land of only around $10 \mathrm{~mm} \mathrm{a}^{-1}$ (Fig. 4b). The relevant sensitivity $\left(\varepsilon_{o}\right)$ is more or less equal to the runoff ratio $(=(P-E) / P$, see Appendix A). That ratio is bounded and varies from near zero in very arid regions to near 1.0 in wet humid regions (Fig. 3b, also see Appendix A). Even with that variation in $\varepsilon_{\mathrm{o}}$ accounted for, it is clear that the projected changes in $\Delta E_{\mathrm{o}}$ were also typically small (Fig. 3d) with a global average of only $+47 \mathrm{~mm} \mathrm{a}^{-1}$. Why is $\Delta E_{\mathrm{o}}$ so small? To address that question we summarised all terms of the surface energy balance (Table 2, Fig. 5).

Our summary of projected changes in the global surface energy balance revealed several key points. The fact that the projected increase in global evaporation over land is smaller than the increase over the ocean has been noted previously (Nohara et al., 2006; Richter and Xie, 2008). Over land, the evaporation increase is relatively small and the increase in incoming long-wave irradiance is mostly partitioned into outgoing long-wave irradiance that is physically related to the projected increase in surface temperature. Hence it is the smaller increase of $E$ over land relative to the ocean that is a major factor permitting the land to warm faster than the ocean in the model projections (Boer, 1993; Sutton et al., 2007).

We took the energy balance analysis one step further than is usual by separating the radiative terms into the respective incoming and outgoing short-wave and long-wave components. That approach clearly revealed the underlying basis of the projected warming that occurs in the climate models. In particular a relatively small top of the atmosphere forcing due to $\mathrm{CO}_{2}$ and other long-lived greenhouse gases is amplified, mostly by water vapour feedback, into a large increase in the incoming long-wave irradiance at the surface (Held and Soden, 2000; Russell et al., 2013). Paradoxically, there is not yet enough warming to be able to confidently test the projected changes against global observations of $P$ and atmospheric water vapour (Liepert and Previdi, 2009; Vonder Haar et al., 2012). In that respect, ongoing monitoring of $P$ and especially the atmospheric water vapour remain 
central. However, the results presented here (Fig. 5) suggest that monitoring the incoming long-wave irradiance at the surface (Philipona et al., 2004, 2005, 2009; Philipona and Durr, 2004) should perhaps have the highest priority.

What is not so well known, yet critical for understanding the projected impacts on water availability, is that most $(81 \%)$ of the realised surface forcing is partitioned into the outgoing long-wave irradiance that is in turn physically related to the increase in surface temperature. Only a small fraction of the realised surface forcing (19\%) enhances the latent heat flux with further small and more or less residual changes in other parts of the surface energy balance (Fig. 5). Because of that, the global sensitivity of $P$ (e.g. $1.6 \% \mathrm{~K}^{-1}$ ) can be used to calculate the flux partitioning $(81 \%, 19 \%)$. This comes about because in that ratio $\left(1.6 \% \mathrm{~K}^{-1}\right)$, the numerator gives the change in global $P$ (and hence $E$ ) $(1.6 \%$ ) whilst the denominator $\left(\mathrm{K}^{-1}\right)$ gives the associated change in the outgoing long-wave irradiance. When put into energetic units the sum of the numerator and denominator give the realised surface forcing. This new integrative framework shows that if the hydrologic cycle were to go faster, say at $7 \% \mathrm{~K}^{-1}$ (e.g. Wentz et al., 2007), then the increase in surface temperature would be smaller for a given realised surface forcing (Fig. 6).

Much public understanding of the projected impacts of climate change on water availability has been based on a conception that an increase in $T$ leads to a faster hydrologic cycle in the sense that the global average $E$ (and hence $P$ ) increases because the temperature increases. That conception is partly true but is not the whole story. The key point is that $E$ depends on many more factors (e.g. humidity, wind, radiation, etc.) than just the surface $T$ (Monteith, 1981). From the point of view of communicating results to other scientists and to the impacts community one can avoid (or at least minimise) confusion by using the conservation of energy as a starting point. That leads directly to the notion that the greater the increase of $E$, the less the surface temperature increases (and vice versa).

Acknowledgements. Parts of this research were first presented in the Dooge Memorial Lectures at the European Geosciences Union Annual Meeting in 2011. We acknowledge Jim Dooge's work as the inspiration for this research. We also acknowledge the modelling groups, the Program for Climate Model Diagnosis and Intercomparison (PCMDIg) and the WCRP's Working Group on Coupled Modeling (WGCM) for their roles in making available the WCRP CMIP3 multi-model data set. Support of this data set is provided by the Office of Science, US Department of Energy. This research was supported by the Australian Research Council (CE11E0098).

Edited by: H. H. G. Savenije

\section{References}

Allen, M. R. and Ingram, W. J.: Constraints on future changes in climate and the hydrologic cycle, Nature, 419, 224-232, 2002.

Arora, V. K.: The use of the aridity index to assess climate change effect on annual runoff, J. Hydrol., 265, 164-177, 2002.

Arrhenius, S.: On the influence of carbonic acid in the air upon the temperature of the ground, Philosoph. Mag., 41, 237-276, 1896.

Boer, G. J.: Climate change and the regulation of the surface moisture and energy budgets, Clim. Dynam., 8, 225-239, 1993.

Budyko, M. I.: Evaporation under natural conditions, Israel Program for Scientific Translations, Jerusalem, 1948.

Budyko, M. I.: Climate and Life, Academic Press, New York, 508 pp., 1974.

Budyko, M. I.: The Earth's Climate: Past and Future, Academic Press, New York, 307 pp., 1982.

Choudhury, B. J.: Evaluation of an empirical equation for annual evaporation using field observations and results from a biophysical model, J. Hydrol., 216, 99-110, 1999.

de Groen, M. M. and Savenije, H. H. G.: A monthly interception equation based on the statistical characteristics of daily rainfall, Water Resour. Res., 42, W12417, doi:10.1029/2006wr005013, 2006.

Donohue, R. J., Roderick, M. L., and McVicar, T. R.: On the importance of including vegetation dynamics in Budyko's hydrological model, Hydrol. Earth Syst. Sci., 11, 983-995, doi:10.5194/hess11-983-2007, 2007.

Donohue, R. J., Roderick, M. L., and McVicar, T. R.: Assessing the differences in sensitivities of runoff to changes in climatic conditions across a large basin, J. Hydrol., 406, 234-244, 2011.

Donohue, R. J., Roderick, M. L., and McVicar, T. R.: Roots, storms and soil pores: Incorporating key ecohydrological processes into Budyko's hydrological model, J. Hydrol., 436-437, 35-50, 2012.

Dooge, J. C. I., Bruen, M., and Parmentier, B.: A simple model for estimating the sensitivity of runoff to long-term changes in precipitation without a change in vegetation, Adv. Water Resour., 23, 153-163, 1999.

Durack, P. J., Wijffels, S. E., and Matear, R. J.: Ocean salinities reveal strong global water cycle intensification during 1950 to 2000, Science, 336, 455-458, 2012.

$\mathrm{Fu}, \mathrm{B}$. P.: On the calculation of the evaporation from land surface, Scienta Atmos. Sin., 5, 23-31, 1981.

Gerrits, A. M. J., Savenije, H. H. G., Veling, E. J. M., and Pfister, L.: Analytical derivation of the Budyko curve based on rainfall characteristics and a simple evaporation model, Water Resour. Res., 45, W04403, doi:10.1029/2008wr007308, 2009.

Grafton, R. Q., Pittock, J., Davis, R., Williams, J., Fu, G., Warburton, M., Udall, B., McKenzie, R., Yu, X., Che, N., Connell, D., Jiang, Q., Kompas, T., Lynch, A., Norris, R., Possingham, H., and Quiggin, J.: Global insights into water resources, climate change and governance, Nat. Clim. Change, 3, 315-321, 2013.

Held, I. M. and Soden, B. J.: Water vapour feedback and global warming, Annu. Rev. Energy Environ., 25, 441-475, 2000.

Held, I. M. and Soden, B. J.: Robust responses of the hydrological cycle to global warming, J. Climate, 19, 5686-5699, 2006. 
IPCC: Climate Change 2007: The Physical Science Basis, in: Contribution of Working Group I to the Fourth Assessment Report of the Intergovernmental Panel on Climate Change, edited by: Solomon, S., Qin, D., Manning, M., Chen, Z., Marquis, M., Averyt, K. B., Tignor, M., and Miller, H. L., Cambridge University Press, Cambridge, UK and New York, USA, 2007.

Johnson, F. and Sharma, A.: Measurement of GCM skill in predicting variables relevant for hydroclimatological assessments, J. Climate, 22, 4373-4382, 2009.

Koster, R. D. and Suarez, M. J.: A simple framework for examining the interannual variability of land surface moisture fluxes, $\mathrm{J}$. Climate, 12, 1911-1917, 1999.

Kumar, S., Lawrence, D. M., Dirmeyer, P. A., and Sheffield, J.: Less reliable water availability in the 21 st century climate projections, Earth's Future, 2, 152-160, doi:10.1002/2013ef000159, 2014.

Levitus, S., Antonov, J., and Boyer, T.: Warming of the world ocean, 1955-2003, Geophys. Res. Lett., 32, L02604, doi:10.1029/2004GL021592, 2005.

Liepert, B. G. and Previdi, M.: Do models and observations disagree on the rainfall response to global warming?, J. Climate, 22, 3156-3166, 2009.

Lim, W. H. and Roderick, M. L.: An Atlas of the Global Water Cycle: Based on the IPCC AR4 models, ANU e-Press, Canberra, 293 pp., 2009.

Lins, H. F. and Slack, J. R.: Streamflow trends in the United States. Geophys. Res. Lett., 26, 227-230, 1999.

Lins, H. F. and Slack, J. R.: Seasonal and Regional Characteristics of U.S. Streamflow Trends in the United States from 1940 to 1999, Phys. Geogr., 26, 489-501, 2005.

Meehl, G. A., Stocker, T. F., Collins, W. D., Friedlingstein, P., Gaye, A. T., Gregory, J. M., Kitoh, A., Knutti, R., Murphy, J. M., Noda, A., Raper, S. C. B., Watterson, I. G., Weaver, A. J., and Zhao, Z.C.: Global Climate Projections, in: Climate Change 2007: The Physical Science Basis, in: Contribution of Working Group I to the Fourth Assessment Report of the Intergovernmental Panel on Climate Change, edited by: Solomon, S., Qin, D., Manning, M., Chen, Z., Marquis, M., Averyt, K. B., Tignor, M., and Miller, H. L., Cambridge University Press, Cambridge, UK and New York, USA, 2007.

Mezentsev, V. S.: More on the calculation of average total evaporation, Meteorol. Gidrol., 5, 24-26, 1955.

Milly, P. C. D.: Climate, soil water storage, and the average annual water balance, Water Resour. Res., 30, 2143-2156, 1994.

Monteith, J. L.: Evaporation and surface temperature, Q. J. Roy. Meteorol. Soc., 107, 1-27, 1981.

Nohara, D., Kitoh, A., Hosaka, M., and Oki, T.: Impact of climate change on river discharge projected by mutilmodel ensemble, J. Hydrometeorol., 7, 1076-1089, 2006.

O'Gorman, P. A. and Schneider, T.: The physical basis for increases in precipitation extremes in simulations of 21stcentury climate change, P. Natl. Acad. Sci., 106, 14773-14777, doi:10.1073/pnas.0907610106, 2009.

Oki, T. and Kanae, S.: Global hydrological cycles and world water resources, Science, 313, 1068-1072, 2006.

Paltridge, G., Arking, A., and Pook, M.: Trends in middle- and upper-level tropospheric humidity from NCEP reanalysis data, Theor. Appl. Climatol., 98, 351-359, 2009.
Philipona, R. and Durr, B.: Greenhouse forcing outweighs decreasing solar radiation driving rapid temperature rise over land, Geophys. Res. Lett., 31, 1-4, 2004.

Philipona, R., Durr, B., Marty, C., Ohmura, A., and Wild, M.: Radiative forcing - measured at Earth's surface - corroborate the increasing greenhouse effect, Geophys. Res. Lett., 31, L03202, doi:10.1029/2003GL018765, 2004.

Philipona, R., Durr, B., Ohmura, A., and Ruckstuhl, C.: Anthropogenic greenhouse forcing and strong water vapor feedback increase temperature in Europe, Geophys. Res. Lett., 32, L19809, doi:10.1029/2005GL023624, 2005.

Philipona, R., Behrens, K., and Ruckstuhl, C.: How declining aerosols and rising greenhouse gases forced rapid warming in Europe since the 1980s, Geophys. Res. Lett., 36, L02806, doi:10.1029/2008GL036350, 2009.

Pielke Sr., R. A.: Heat storage within the earth system, B. Am. Meteorol. Soc., 84, 331-335, 2003.

Pike, J. G.: The estimation of annual runoff from meteorological data in a tropical climate, J. Hydrol., 2, 116-123, 1964.

Ramanathan, V. and Vogelmann, A. M.: Greenhouse effect, atmospheric solar absorption and the earth's radiation budget: From the Arrhenius-Langley era to the 1990's, Ambio, 26, 38-46, 1997.

Renner, M. and Bernhofer, C.: Applying simple water-energy balance frameworks to predict the climate sensitivity of streamflow over the continental United States, Hydrol. Earth Syst. Sci., 16, 2531-2546, doi:10.5194/hess-16-2531-2012, 2012.

Richter, I. and Xie, S.-P.: Muted precipitation increase in global warming simulations: A surface evaporation perspective, J. Geophys. Res., 113, D24118, doi:10.1029/2008jd010561, 2008.

Roderick, M. L. and Farquhar, G. D.: A simple framework for relating variations in runoff to variations in climatic conditions and catchment properties, Water Resour. Res., 47, W00G07, doi:10.1029/2010wr009826, 2011.

Roderick, M. L., Sun, F., and Farquhar, G. D.: Water cycle varies over land and sea, Science, 336, 1230-1231, 2012.

Rotstayn, L. D., Cai, W., Dix, M. R., Farquhar, G. D., Feng, Y., Ginoux, P., Herzog, M., Ito, A., Penner, J. E., Roderick, M. L., and Wang, M.: Have Australian rainfall and cloudiness increased due to the remote effects of Asian anthropogenic aerosols?, J. Geophys. Res., 112, D09202, doi:10.01029/02006JD007712, 2007.

Russell, G. L., Lacis, A. A., Rind, D. H., Colose, C., and Opstbaum, R. F.: Fast atmosphere-ocean model runs with large changes in $\mathrm{CO}_{2}$, Geophys. Res. Lett., 40, GL056755, doi:10.1002/2013g1056755, 2013.

Savenije, H.: Review Comment, Hydrol. Earth Syst. Sci. Discuss., 10, C7524-C7527, 2014.

Sherwood, S. C., Roca, R., Weckwerth, T. M., and Andronova, N. G.: Tropospheric water vapor, convection, and climate, Rev. Geophys., 48, RG2001, doi:10.1029/2009rg000301, 2010.

Sutton, R. T., Dong, B., and Gregory, J. M.: Land/sea warming ratio in response to climate change: IPCC AR4 model results and comparison with observations, Geophys. Res. Lett., 34, L02701, doi:10.1029/2006GL028164, 2007.

Trenberth, K. E., Fasullo, J. T., and Kiehl, J. T.: Earth's global energy budget, B. Am. Meteorol. Soc., 90, 311-323, 2009.

Turc, L.: Le bilan d'eau des sols, Relation entre les précipitations, l'évaporation et l'écoulement, Ann. Agron., 5, 491-569, 1954. 
Vonder Haar, T. H., Bytheway, J. L., and Forsythe, J. M.: Weather and climate analyses using improved global water vapor observations, Geophys. Res. Lett., 39, L15802, doi:10.1029/2012g1052094, 2012.

Wentz, F. J., Ricciardulli, L., Hilburn, K., and Mears, C.: How much more rain will global warming bring?, Science, 317, 233-235, 2007.

Wild, M., Folini, D., Schär, C., Loeb, N., Dutton, E., and KönigLanglo, G.: The global energy balance from a surface perspective, Clim. Dynam., 40, 3107-3134, 2013.

Wu, P., Christidis, N., and Stott, P.: Anthropogenic impact on Earth's hydrological cycle, Nat. Clim. Change, 3, 807-810, 2013.
Yang, D., Sun, F., Liu, Z., Cong, Z., Ni, G., and Lei, Z.: Analyzing spatial and temporal variability of annual water-energy balance in nonhumid regions of China using the Budyko hypothesis, Water Resour. Res., 43, W04426, doi:10.1029/2006WR005224, 2007.

Yang, H., Yang, D., Lei, Z., and Sun, F.: New analytical derivation of the mean annual water-energy balance equation, Water Resour. Res., 44, W03410, doi:10.1029/2007WR006135, 2008.

Zhang, L., Dawes, W. R., and Walker, G. R.: Response of mean annual evapotranspiration to vegetation changes at catchment scale, Water Resour. Res., 37, 701-708, 2001. 


\section{Appendix A}

\section{Derivation of alternative sensitivity coefficients by Prof. H. Savenije}

While this paper was under review, the journal editor presented an alternative derivation of the sensitivity coefficients (i.e. alternative to Eqs. 2-4 in main text) based on an alternative mathematical form of the Budyko curve (de Groen and Savenije, 2006; Gerrits et al., 2009). The new derivation was novel and offered advantages for the physical interpretation of the sensitivity coefficients (Savenije, 2014). An overview of this new derivation due to Prof Savenije is presented here to aid in the physical interpretation of the sensitivity coefficients $\left(\varepsilon_{\mathrm{P}}, \varepsilon_{\mathrm{o}}\right)$ in the main text.

The form of the Budyko curve we used is (see Eq. 1 in main text),

$E=\frac{P E_{\mathrm{o}}}{\left(P^{n}+E_{\mathrm{o}}^{n}\right)^{1 / n}}$.

In the review of our article, Prof Savenije began with the Schreiber form of the Budyko curve,

$E=P\left(1-e^{-\left[\frac{E_{0}}{P}\right]}\right)$.

Note that Eq. (A2) reproduces the climate model output (Fig. A1). This implies that Eq. (A2) is more or less numerically identical to Eq. (A1) when $n=1.5$ (see Fig. 2 caption).

Numerically either equation is an adequate description for our purpose. Equation (A1) has the advantage that the adjustable parameter, $n$, can be varied to describe real catchments (see discussion in main text). Equation (A2) has the advantage that the sensitivity coefficients take a particularly simple form. To see that, we start with Eq. (4) from the main text,

$$
\begin{aligned}
\mathrm{d}(P-E) & =\left(1-\frac{\partial E}{\partial P}\right) \mathrm{d} P-\frac{\partial E}{\partial E_{\mathrm{o}}} \mathrm{d} E_{\mathrm{o}} \\
& =\varepsilon_{\mathrm{P}} \mathrm{d} P-\varepsilon_{\mathrm{o}} \mathrm{d} E_{\mathrm{o}} .
\end{aligned}
$$

Calculating the sensitivity coefficients using Eq. (A2) we get,

$$
\frac{\partial E}{\partial P}=\frac{-E_{\mathrm{o}}}{P} e^{-\frac{E_{0}}{P}}-e^{-\frac{E_{0}}{P}}+1
$$

and after some rearrangement and simplification we find,

$\varepsilon_{\mathrm{P}}=1-\frac{\partial E}{\partial P}=\left(\frac{P-E}{P}\right)\left(\frac{E_{\mathrm{o}}}{P}+1\right)$.

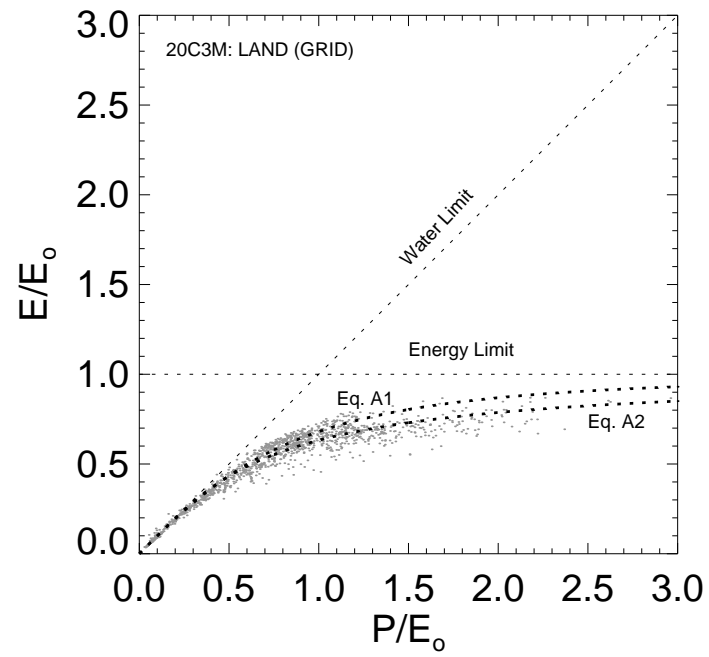

Fig. A1. Comparison of the two alternate forms (Eq. A1 vs. Eq. A2) of the Budyko curve. All else is the same as Fig. 2e in the main text.

Similarly,

$\varepsilon_{\mathrm{o}}=\frac{\partial E}{\partial E_{\mathrm{o}}}=e^{-\frac{E_{0}}{P}}=\left(\frac{P-E}{P}\right)$.

Putting those two results into Eq. (A3) we have,

$$
\begin{aligned}
\mathrm{d}(P-E)= & \left(\frac{P-E}{P}\right)\left(\frac{E_{\mathrm{o}}}{P}+1\right) \mathrm{d} P \\
& -\left(\frac{P-E}{P}\right) \mathrm{d} E_{\mathrm{o}} .
\end{aligned}
$$

The advantages of this form for physical interpretation become very clear. First, we note that $(P-E) / P$ is simply the runoff ratio. In other words the sensitivity of $P-E$ to variations in net irradiance $\left(E_{\mathrm{o}}\right)$ is determined by the runoff ratio. Secondly, $E_{\mathrm{o}} / P$ is known as the aridity index, Hence it is clear that the sensitivity of $P-E$ to variations in $P$ depends on the runoff ratio and an enhancement that depends on the aridity index.

We found that $\mathrm{d} E_{\mathrm{o}}$ is generally small in the model projections (Fig. 3d). If we ignore those variations in this instance we have,

$\mathrm{d}(P-E) \approx\left(\frac{P-E}{P}\right)\left(\frac{E_{\mathrm{o}}}{P}+1\right) \mathrm{d} P$,

as a simple form that provides physical guidance to the interpretation. 